\title{
A CONSTRUÇÃO DA INTEGRALIDADE NO TRABALHO COTIDIANO DA EQUIPE SAÚDE DA FAMÍLIA
}

\author{
The construction of integrality in the daily work of health family team \\ La construcción de la integralidad en el trabaj o cotidiano del equipo de salud familiar
}

Selma Maria da Fonseca Viegas ${ }^{1}$

Cláudia Maria de Mattos Penna

\section{RESUMO}

Trata-se do recorte de uma tese de doutorado de abordagem qualitativa, delineada pela estratégia de pesquisa Estudo de Casos Múltiplos Holísticos, com objetivo de compreender a construção das práticas de integralidade em saúde no trabalho cotidiano das equipes de Saúde da Família e de gestores de três municípios do Vale do Jequitinhonha-MG. Foram entrevistados 48 trabalhadores das equipes Saúde da Família e de apoio, além dos secretários municipais. Apresenta-se uma das categorias de análise que mostra a importância dada ao trabalho em equipe multiprofissional e o reconhecimento da necessidade do trabalho do outro, isto é, a complementaridade e a interdependência das ações para prestar uma assistência integral e resolutiva. Algumas equipes apresentaram ações interdisciplinares com uso das diferentes habilidades na identificação e resolução dos problemas. Outras convivem com ações individualizadas, mas referem a necessidade de responsabilidade compartilhada nas ações e decisões da equipe para alcançar a integralidade em saúde.

Palavras-chave: Assistência integral à saúde. Programa Saúde da Família. Trabalho. Pessoal de saúde.

\begin{abstract}
This is an excerpt from a PhD thesis of a qualitative approach outlined by the strategy of search of Holistic Multiple Case Study which aims to understand the construction of the comprehensive health practices in the daily work of the family health teams and the managers of three municipalities in Vale do Jequitinhonha-MG. The study subjects were professionals from the Family Health Teams, support staff and municipal secretaries in a total of 48 workers. It is presented one of the categories of analysis that shows the importance given to multiprofessional teamwork and the acknowledgement of the necessity of other's work, that is, complementarity and interdependence of actions to provide a total and effective assistance. Some teams have disciplinary actions with the use of different skills in identifying and solving problems. Others have individual actions but refer to the need of shared responsibility in actions and decisions of the team to achieve the integrality in health.
\end{abstract}

Keywords: Comprehensive Health Care. Family Health Program. Work. Health Personnel.

\section{Resumen}

Se trata de un recorte de una tesis doctoral de enfoque cualitativo delineada por la estrategia de investigación "Estudio de Casos Múltiples Holísticos", con el fin de comprender la construcción de las prácticas integrales de salud en el trabajo diario de los equipos de salud de la familia y los administradores de tres municipios del Vale de Jequitinhonha (MG). Los entrevistados son 48 trabajadores de los Equipos de Salud de la Familia y de apoyo, además de los secretarios municipales. Se presenta una de las categorías de análisis que evidencia la importancia dada al trabajo en equipo multiprofesional y el reconocimiento de la necesidad del trabajo del otro, es decir, la complementariedad y la interdependencia de las medidas para proporcionar una atención integral y eficaz. Algunos equipos tienen las medidas disciplinarias con el uso de diferentes habilidades para identificar y resolver problemas. Otros tienen acciones individuales, pero que se refieren a la necesidad de la responsabilidad compartida en las acciones y decisiones del equipo para lograr una salud completa.

Palabras claves: Atención Integral de Salud. Programa de Salud Familiar. Trabajo. Personal de Salud.

\footnotetext{
${ }^{1}$ Doutora em Enfermagem pela Escola de Enfermagem da Universidade Federal de Minas Gerais. Belo Horizonte - MG. Brasil. E-mail: selmamfv@yahoo.com.br; ${ }^{2}$ Docente - Associado. Programa de Pós-Graduação em Enfermagem - UFMG. Doutora em Filosofia da Enfermagem - UFSC; Pós-doutorado em Ciências Sociais - Université René Descartes - Paris V - Sorbonne. Belo Horizonte - MG. Brasil. E-mail: cmpenna@enf.ufmg.br
} 


\section{INTRODUÇÃO}

A integralidade propõe a ampliação e o desenvolvimento do cuidar nas profissões da saúde e não se define, apenas, como uma diretriz básica do Sistema Único de Saúde (SUS). Pode ser percebida como um conjunto de noções pertinentes a uma assistência ampliada, com articulação das ações dos profissionais, em uma visão abrangente do ser humano dotado de sentimentos, desejos, aflições e racionalidades.

Isso significa dizer que a integralidade "deverá ser construída cotidianamente, por permanentes interações democráticas dos sujeitos, pautada por valores emancipatórios fundados na garantia da autonomia, no exercício da solidariedade e no reconhecimento da liberdade de escolha do cuidado e da saúde que se deseja obter"1:175.

Como princípio doutrinário constitucional e fundamental do SUS, a integralidade inscreve-se como um grande desafio da Saúde no Brasil, no processo de construção, implantação e consolidação de um modelo assistencial que tem sua base e suas diretrizes fundamentadas na promoção, prevenção, cura e reabilitação. Isso implica em ações voltadas para a qualidade de vida das pessoas. Dessa forma, a Estratégia Saúde da Família (ESF) constitui-se em um importante desafio ao prever uma ruptura com o modelo assistencial biomédico e a construção de uma nova prática, centrada no usuário. Para tanto, necessita de práticas remodeladas que visem um novo modo de construir o cuidado e o forjamento de novos sujeitos em ação, comprometidos radicalmente com a defesa da vida individual $e$ coletiva dentro de uma ótica de direitos sociais plenos².

No cotidiano das equipes da ESF, a integralidade opera nos microprocessos de trabalho em saúde, nos fazeres de cada profissional que adota uma postura acolhedora e compromissada com os usuários, seus cuidados e a cura, ao estabelecer vínculo, condutas e prioridades equânimes para assisti-los em função de suas necessidades ${ }^{1-3}$. Para que a construção da integralidade se concretize, é necessário que cada profissional utilize seu potencial criativo de forma integrada com a equipe em um esforço coordenado para a produção e a promoção de seu cuidado em prol do usuário. Porém, na prática, essa Estratégia ainda não conseguiu alcançar seus objetivos, pois a assistência, em várias realidades, ainda se fundamenta no modelo médico-centrado, com enfoque na doença e com atenção fragmentada.

A perspectiva da integralidade das ações favorece uma ação inter/transdisciplinar. Para tanto, é imprescindível o desenvolvimento de uma prática comunicativa orientada para o entendimento mútuo. Assim, a abordagem integral dos indivíduos/famílias na ESF é facilitada pela soma de olhares dos distintos profissionais que compõem as equipes interdisciplinares. Dessa maneira, nos fazeres do cotidiano de cada profissional, pode-se obter um maior impacto sobre os diferentes fatores que interferem no processo saúde-doença. Para o desenvolvimento de ações de saúde na perspectiva da integralidade, faz-se necessária uma aproximação integral entre os sujeitos que prestam o cuidado ${ }^{6}$.

Nessa perspectiva, é possível compreender a focalização no contexto das práticas de saúde na Atenção Primária à Saúde (APS) com sentidos na materialização da integralidade, assim como nas estratégias de consolidação da própria universalização e da equidade, que espelham os grandes desafios de concretização do direito à saúde em um país de profundas desigualdades como o Brasil'.

Destarte, a ESF constitui a porta de entrada do Sistema de Saúde, em uma abordagem primária que forma a base e determina o trabalho dos outros níveis de atenção, oferecendo serviços de promoção e proteção à saúde, prevenção de riscos, cura e reabilitação para maximizar a saúde e o bem-estar, e integrando a atenção de forma hierarquizada e regionalizada ${ }^{4}$. Essa compreensão vem reforçar a importância da APS na oferta de serviços públicos, como "um dos loci mais importantes para a consolidação dos princípios do SUS, no qual a integralidade da atenção é o amálgama dos demais princípios e fundamenta o cuidado como uma tecnologia de saúde" 1:82.

Nesse sentido, "o termo integralidade expressa um conjunto de valores que devem pautar todas as práticas de saúde, conferindo-lhes qualidades"5:778.

Nesse contexto o objetivo do estudo é compreender a construção das práticas de integralidade no trabalho em saúde na perspectiva de profissionais das equipes de Saúde da Família, das equipes de apoio e de gestores de municípios do Vale do Jequitinhonha.

\section{MÉTODO}

0 estudo é de abordagem qualitativa, delineada pela estratégia de pesquisa Estudo de Casos Múltiplos Holísticos, fundamentado na Sociologia Compreensiva do Cotidiano, originado de uma tese de doutorado ${ }^{7}$. Apresenta-se uma das categorias de análise que relaciona a necessidade do trabalho em equipe como preceito para a consolidação da integralidade na Estratégia Saúde da Família.

Considerando que é no plano das práticas cotidianas, de profissionais da ESF, da equipe de apoio e de gestores que se dá a construção da integralidade com suas várias interpretações, fez-se a opção por lançar o olhar da Sociologia Compreensiva do Cotidiano $^{8}$ sobre o objeto de estudo, para compreender a integralidade por meio da pluralidade de visões e experiências no cotidiano de trabalho dos profissionais. Pois, "a sociedade não é apenas um sistema mecânico de relações econômico-políticas ou sociais, mas um conjunto de relações interativas, feito de afetos, emoções, sensações que constituem, stricto sensu, o corpo social" ${ }^{\prime: 73}$.

Utilizaram-se três casos neste estudo, fundamentandose nas evidências resultantes de estudos de casos múltiplos em que é possível usar a replicação literal, e as "conclusões analíticas que independentemente surgiram dos três casos 
foram mais contundentes do que aquelas que surgem apenas de um caso"; e se, sob circunstâncias variadas, ainda se pôde chegar a "conclusões comuns a partir de ambos os casos, essas estenderam de forma incomensurável a capacidade externa de generalização das descobertas no estudo":76.

0 universo de estudo foi constituído por municípios situados no Vale do Jequitinhonha, Minas Gerais (MG), Brasil: Diamantina, Gouveia e Datas. A proposta foi realizar um estudo de caso individual em cada um desses municípios, constituindose um estudo de casos múltiplos, com unidade única de análise. Cada caso em particular consiste em um estudo "completo", no qual se procuram evidências convergentes ou divergentes com respeito aos fatos e às conclusões para o caso ${ }^{9}$.

Os sujeitos desta pesquisa foram trabalhadores das equipes da ESF e das equipes de apoio, entre médicos, enfermeiros, auxiliares/técnicos de enfermagem, agente comunitário de saúde (ACS), cirurgião-dentista, auxiliar de consultório dentário, fisioterapeuta e os gestores de cada município - secretários de saúde com acúmulo de função gerencial, cujas participações foram voluntárias, em um total de 48 participantes. Como critério de inclusão, estabeleceu-se a atuação de, no mínimo, um ano na função/cargo de trabalho.

A pesquisa de campo, durante um período de oito meses, teve por base um levantamento de dados primários por meio de observação direta de natureza descritiva, realizada de forma sucessiva nos três municípios, nos ambientes de trabalho do participante - Unidade de Saúde, domicílio, comunidade. 0 registro dessas observações foi feito em um diário de campo elaborado após cada período de observação, identificada como "notas de observação (NO)". Após a observação, realizou-se entrevista individual aberta, de forma simultânea, com os sujeitos de pesquisa, que foram gravadas e transcritas na íntegra.

A análise de dados foi feita com base no referencial de Bardin ${ }^{10}$, utilizando-se a técnica da Análise de Conteúdo Temática, ou seja, uma análise dos "significados".

A pesquisa foi desenvolvida segundo as diretrizes e normas regulamentadoras de pesquisas envolvendo seres humanos, a Resolução CNS 196/96. A coleta de dados iniciouse após a aprovação do projeto pelo Comitê de Ética da Universidade Federal de Minas Gerias (COEP UFMG), de acordo com o Parecer n ${ }^{\circ}$ ETIC 142/08. 0 acesso ao campo de pesquisa foi obtido por meio de autorização dos prefeitos e secretários de saúde dos municípios para conduzir o estudo, além do consentimento livre e informado dos participantes. 0 anonimato dos sujeitos foi garantido por meio da adoção de siglas enumeradas, referentes à primeira letra que identifica cada profissão, seguida pelo número de acordo com aproximação.

\section{RESULTADOS E DISCUSSÃO}

0 trabalho em equipe na saúde representa um processo de relações a serem pensadas pelos próprios trabalhadores $\mathrm{e}$ tem múltiplas possibilidades de significados quando realizado na perspectiva de uma atenção integral.

A compreensão de integralidade remete, à integração da equipe, reconhecendo a interdependência dos atores na produção do cuidado à saúde:

Eu compreendo por integralidade... é uma participação de várias pessoas na saúde da população. Então, eu penso assim, tem que ter uma integralidade muito grande entre o médico, a auxiliar de enfermagem, o técnico de enfermagem, a enfermeira, o bioquímico que faz os exames de laboratório, aquelas duas lá em Palmital (distrito), que fazem as visitas e vão olhar as pressões, aquilo ali é muito importante. Tem que haver integralidade entre todas essas pessoas que trabalham, com um relacionamento muito bom e com muito respeito $\left(M_{5}\right)$.

(Integralidade) Eu acho que é a equipe estar mais unida, trabalhando junto, a equipe toda no mesmo sentindo, lutando por um mesmo objetivo $\left(A E_{5}\right)$.

Eu digo assim, integralidade, integra toda a equipe pra um bem maior que é o quê? A qualidade na assistência. E essa qualidade na assistência vai gerar uma qualidade de vida, que na verdade o que é? A saúde da população. Então, eu entendo integralidade como isso, todo mundo unido, integrado pro bem maior que éa saúde da população $\left(E_{4}\right)$.

0 trabalho em equipe representa um dos principais pilares para uma assistência integral e equânime na saúde. Assim, uma abordagem integral dos indivíduos/famílias pode ser facilitada pela soma de olhares dos distintos profissionais que compõem as equipes de Saúde da Família e favorecer uma ação interdisciplinar. Dessa maneira, é necessário que o trabalho em equipe seja norteado por um processo assistencial comum e que os profissionais desenvolvam uma ação de interação entre si e com a comunidade.

Para tanto, é imprescindível o desenvolvimento de uma prática comunicativa orientada para o entendimento mútuo e, assim, obter um maior impacto sobre os diferentes fatores que interferem no processo saúde-doença, constituindo dessa forma uma prática profissional que se reconstrua interdisciplinariamente na prática do outro e consiga se transformar em intervenção coletiva na realidade onde se inserem ${ }^{11}$.

Na pesquisa de campo, verificamos que atender as necessidades dos usuários pressupõe empenho da equipe ESF na resolução dos problemas de saúde de suas famílias. Sem o trabalho em equipe, não será possível implementar o modelo de atenção que acolhe, que escuta as pessoas, ou seja, voltado 
a resolver os problemas de saúde das pessoas e da comunidade, de forma coparticipativa:

Integralidade... Nossa Senhora, meu Deus! Integralidade, bom eu compreendo que é um atendimento igualitário. Pra todos, é um... atendimento multidisciplinar. Abordando o paciente, não só a patologia dele. Mas abordar o paciente na história familiar dele. Igual mesmo, dar mais... Eu sempre falo isso com os médicos, com a nutricionista, dar mais atenção ao ACS, porque é ele que sabe na íntegra, a integralidade do paciente, é ele que vai a casa, ele que conhece, então eu entendo como isso, como a gente trabalhar em conjunto, trabalhar junto não só equipe, mas também paciente. Paciente, familia, comunidade, crenças, valores. A gente tem que respeitar a integralidade de um paciente pra eu conseguir fazer o tratamento dele $\left(E_{5}\right)$.

Assim, é necessário que o trabalho seja articulado com o saber/fazer do ACS, pois é esse trabalhador que detém 0 saber "da íntegra do usuário", é ele que está mais próximo das pessoas e das famílias que acompanha. Ou seja, a necessidade de outras profissões para não continuar com uma prática dissociada da equipe, e não manter o processo de trabalho naquilo que se considera como parte da sua prática individual, portanto, apesar de a fala explicitar "um atendimento multidisciplinar", o trabalho cotidiano descrito aponta a interdisciplinaridade nas ações.

A equipe de saúde, "em busca de implementar um enfoque integral, teria que se transformar em uma "interseção transitada", não no sentido de espaço onde trajetórias diferentes se cruzam, mas de uma estrutura difusa onde trajetórias entram em circuitos autorregulados que possibilitam uma complementação de perspectivas e com isso aproximam do momento criativo do surgimento do "entre-disciplinar". A busca não tem que estar atrás de um indivíduo que encarne a integralidade - embora seja necessário que os membros individuais tenham uma "mente" mais plástica, mais flexível, do que especializada - mas de um "associado" que facilite a circulação entre saberes. Não se trata de aprender a transitar o caminho dos outros, mas de saber que se faz o caminho ao andar - isto é, de ter a coragem de andar sem um caminho certo"12:126.

0 enfermeiro, ao abordar o "trabalho em conjunto" não somente com a equipe, mas também com o "paciente, família, comunidade, crenças, valores" remete-nos à integralidade, considerando não somente a objetividade na assistência à saúde, mas também a subjetividade da vivência coletiva. Esse é um artifício prático para despertar o senso de habilidade profissional de relacionar o ser em seu ambiente diverso e suas relações culturais que, compreensivelmente, pode esconder- nos fatos e fatores importantes para a relação do cuidado e 0 significado dado pelo usuário ao processo cuidado-saúdedoença. Por isso, "compreender a cultura de um povo expõe a sua normalidade sem reduzir sua particularidade"13:24. Isso quer dizer, dentro do contexto dado pelo sujeito do estudo $E_{5}$, ao considerar um "trabalho conjunto", que "quanto mais eu tento seguir o que fazem esses usuários, mais lógicos e singulares eles me parecem". Isso os torna mais acessíveis: colocá-los no quadro de suas próprias banalidades dissolve sua opacidade ${ }^{13: 24}$. A proximidade leva a conhecer a pessoa e sua família e a considerar as particularidades na atenção à saúde.

Ainda, nos relatos desses informantes, foi considerado um fator relevante: todos os profissionais da equipe são importantes para o trabalho integral em saúde. Embora pertençam a uma equipe, esses profissionais podem não atender a um objetivo comum, levando em consideração a subjetividade e as diferentes práticas e saberes. Nesse sentido, foi focado o relacionamento humano. 0 trabalho é permeado por diferenças e por pontos de convergência que configuram a relação diária no cotidiano dos Serviços. Essa atuação em equipe para a construção da integralidade não deve ser pensada fora das relações dos sujeitos, que foi abordada como "muito difícil":

A integralidade acaba sendo uma questão muito difícil, porque a integralidade, às vezes, é... às vezes não, é 100\% relacionamento humano, eu penso assim. [...] e esse relacionamento humano não só com os pacientes, mas também com a equipe que você trabalha, é muito difícil, às vezes, é muito dificil! Porque por mais que você ajuda, você quer fazer um serviço bem feito, mas você não trabalha sozinho, você trabalha em equipe, você depende de quê? Você depende da equipe. [...] Com outros profissionais, psicólogo, nutricionista, assistente social, fisioterapeuta, não tem problema nenhum, é muito bom o relacionamento com eles, a integração com eles é muito boa. Às vezes, o que dificulta mais é a integração médico com enfermeiro $\left(E_{4}\right)$.

Na organização do processo de trabalho em saúde, é importante a dinâmica comunicação e integração entre a equipe formal da Saúde da Família e os demais membros da equipe de apoio da Unidade, pois a própria característica da prestação de serviços de assistência em saúde exige uma interação que dê suporte ao atendimento, rompendo com o modelo de divisão do trabalho e desigual valoração social dos trabalhadores. Verifica-se o desencontro entre o médico e o enfermeiro quando se fala da integração entre os membros distintos da equipe saúde. 0 enfermeiro, por estar mais próximo da comunidade, acolhe os usuários e traz, para dentro dos Serviços, demandas da comunidade gerando novas ações. No entanto, o médico ainda permanece, quase no período integral de seu trabalho, 
confinado ao consultório atendendo à demanda da consulta, fato que acontece principalmente pela permanência da cultura médica formal: consulta/consultório. Assim, ao deparar-se com essa demanda diária, o enfermeiro necessita de ações médicas para responder às necessidades do usuário/família, o que provoca uma "necessidade de negociação" (NO) para o atendimento do profissional médico. 0 trabalho em equipe de saúde ainda se baseia em uma relação de hierarquia e subordinação, inquestionável hegemonia por tradição, já que o papel da liderança médica existe desde antes da existência dos Serviços de Saúde. Aparece nesse depoimento uma dimensão que reproduz uma necessidade de conquista de espaço, que por si só demonstra a desigualdade no estabelecimento das relações.

0 "trabalho não é apenas uma atividade; ele é, também, uma forma de relação social, o que significa que ele se desdobra em um mundo humano caracterizado por relações de desigualdade, de poder e de dominação"14:32. Portanto, "o real do trabalho, não é somente o real do mundo objetivo; ele é, também, o real do mundo social"14:32.

"O não trabalhar em equipe gera nos enfermeiros a sensação de estarem sozinhos ao executar as ações de saúde com a população, pois estes não conseguem estabelecer ações coletivas com os médicos"15:562.

Nessa realidade, o trabalho em equipe é desenvolvido em interações presenciais na forma de reuniões mensais e em algumas atividades trabalhadas conjuntamente - como exemplo, os grupos operativos observados - executados pelo enfermeiro, o nutricionista, o médico, o auxiliar de enfermagem e os ACS. A maior parte das equipes observadas tem incorporado a seu dia a dia pelo menos alguns elementos de interação, envolvendo comunicação verbal informal nos corredores da Unidade, na porta do consultório ou em algum setor da Instituição (NO). Todos manifestam saber o que é uma equipe, mas o que se manifesta é a dificuldade da clara visão do que seja formar uma equipe porque, muitas vezes, predominam ações individuais, portanto, fragmentadas.

A abordagem das relações sociais do trabalho e as vivências subjetivas, as articulações do singular e do coletivo, aponta para que os impasses do individualismo se confirmem mais equivocados, pois este não funciona unicamente como beco sem saída, mas se constitui numa tática eficaz para tornar necessária a reabertura ao debate sobre a organização do trabalho ${ }^{16}$.

A direção do processo de trabalho, para promoção de ações integrais em saúde, possibilita um compartilhamento das responsabilidades com todos os atores da equipe saúde e, sobretudo, com o gestor. Assim, todos devem agir em conjunto numa única direção, claramente definida mediante as políticas de saúde e os pressupostos que norteiam essa Estratégia.

0 enfrentamento da complexidade dos problemas de saúde da população requer, além de reconhecer o ser como integral, realizar um trabalho em equipe, também, de forma integral:
Integralidade significa ser integral. Então, por exemplo, quando eu estou com o paciente eu tenho que vê-lo de uma forma integral, não fisicamente, mas na forma social, psicológica, as condições de vida desse paciente. Então, pra mim, a ESF foi um ganho muito grande por isso, porque a gente conhece o paciente, não o braço e a perna, ou às vezes, só o braço ou às vezes, só a perna, mas ele como um ser que sente, que tem suas ansiedades, seus desejos, tem as suas dificuldades, e a gente consegue ver essa integralidade tão profunda porque a gente conhece a casa, a gente conhece, mais ou menos, a relação das pessoas dentro dessa casa, as condições financeiras, as condições de saneamento básico dessa casa, dessa família. Então, quando o paciente vem aqui, a gente já sabe mais ou menos, um pouco de tudo sobre ele. Então, isso eu entendo como integralidade, atendêlo de uma forma integral, não física e biologicamente, mas de uma forma mais social. $E$ a integralidade da equipe também, que eu acho importante, a equipe tem que estar integrada não sei se significa isso... Mas, é uma equipe onde um ajuda o outro... Não onde um faz a sua parte, e 0 outro faz a sua parte, cada um ajudando o outro a fazer o todo. Ea gente tenta trabalhar aqui $\left(E_{1}\right)$.

Na ESF consegue-se ver essa integralidade por conhecer a pessoa como "um ser que sente, que tem suas ansiedades, seus desejos e suas dificuldades..." A abordagem do ser social é possibilitada pela territorização, pela responsabilização da equipe no atendimento às famílias de sua área de abrangência, pelo vínculo estabelecido, enfim pela nova proposta de assistência na atenção primária, a ESF, como promotora da abordagem do "ser completo".

Acrescenta que, para alcançar a integralidade, é necessária uma equipe integrada na qual "cada um ajuda o outro a fazer o todo". Segundo o informante, os profissionais devem se unir, ou seja, deve haver o vínculo à equipe, com objetivo de otimizar resultados. "A responsabilidade institucional dos profissionais e das equipes é vista como a 'pedra de toque' na constituição de processos de trabalho mais cuidadores" $17: 82$, o que pode ser constatado no relato abaixo:

A gente trabalha tão junta que no meu fluxograma de atendimento ao acolhimento eu coloquei enfermeiro separado do médico, e aínão deu certo e nós juntamos novamente. Então, eu tento fazer um trabalho integral não só aqui na equipe. Agora, por exemplo, com as Linhas Guias, vai ter uma integralidade, todo mundo falando a mesma língua. 
Então eu acho que, se a gente andar de uma forma integral, flui melhor. $E$ quando eu falo integral também não só a equipe, mas as instituições as quais nos respaldam, por exemplo, os especialistas. Nós aqui temos uma dificuldade, muito, com a atenção a saúde mental, não é tão integral como deveria ser. É... com a assistência social, que é muito importante, e a gente tem que trabalhar em cima disso pra que melhore, mas pelo menos na equipe básica aqui, a gente já faz um trabalho mais integral, todo mundo integrado naquela pessoa, no trabalho, todo mundo falando a mesma língua $\left(E_{1}\right)$.

Nesse sentido, gerir o trabalho em saúde rumo à integralidade da atenção e do cuidado em saúde requer, reflexões sobre as características dos processos desenvolvidos nas práticas de cada profissional, explicitamente fragmentadas, como essas são organizadas, identificadas e como respondem às necessidades dos usuários ${ }^{18}$.

Ser uma equipe na ESF pressupõe conhecer a realidade territorial e das famílias para proceder a atenção à saúde:

Nós somos uma equipe com sete agentes, quatro auxiliares, a enfermeira [...] a gente ir nas casas das pessoas, conhecer a familia delas, os problemas, as dificuldades [...] Referir essa paciente, às vezes, para uma psicóloga, ou para uma assistente social, para um fisioterapeuta, assumir ela aqui na nossa Unidade, sabe? Desde a casa dela até a Unidade, igual o pessoal faz aqui, os grupos de caminhada, é pegar desde a fase preventiva, curativa, informativa, eu acho legal a gente fazer isso nos grupos. Informar o paciente para ele ter consciência de que ele consegue com isso aí fazer a saúde dele ficar um pouco melhor $\left(M_{7}\right)$.

0 médico aponta caminhos quando fala que a equipe precisa ir às casas e conhecer o contexto de vida das pessoas para poder definir o itinerário terapêutico que possa atender a suas necessidades. Isso pode ser aqui compreendido como uma referência à responsabilização territorial da equipe, quando menciona "mas tentar assumir isso pra gente, nós somos uma equipe". Ao conhecer a família e realizar um diagnóstico situacional, o profissional pode encaminhá-la a outro nível de atendimento ou para ações intersetoriais, quando se faz necessário. Nessa percepção, a trilha está posta, portanto, 0 que se precisa fazer, mesmo a pequenos passos, é percorrê-la.

Os profissionais de saúde, por meio de trabalho intersetorial, podem - e devem - apoiar a comunidade para que ela vença suas dificuldades, lute por seus direitos no enfrentamento dos problemas vividos na sua realidade cotidiana.
Para tanto, é necessário que, além da capacidade científica, do domínio técnico e da ação política, exista o investimento para fortalecimento e conquista da autonomia para a tomada de decisão que envolve tanto o desejo do indivíduo quanto o da coletividade.

Integralidade em saúde, na minha concepção, é você conseguir conscientizar os profissionais de saúde da necessidade de compreender que o paciente é um ser humano como um todo. Eu acho que a gente ainda peca por isso, de ver o paciente por sistemas em vez de ver um paciente como um todo. Então a integralização, além do paciente não ser visto como um todo, os próprios profissionais, eles trabalham individualmente, não existe um relacionamento entre eles. Por exemplo, você encaminha um paciente para um ortopedista, ou pra um psicólogo, ou pra um gastroenterologista, ou pra um neurologista, não existe um feed-back, não existe um retorno que se possa trabalhar em conjunto. Às vezes, eu consigo isso quando o médico trabalha comigo no município, se tenho uma nutricionista, uma psicóloga ou uma ginecologista que tem aqui e a gente consegue trocar uma ideia, aí a gente consegue fazer dentro do possível um trabalho conjunto, integralizado, mas na grande maioria das vezes, o paciente, ele é como se fosse dividido em pedaços, e não se consegue tratá-lo como um todo: a parte social, cultural, emocional, mental, financeira, étnica, hereditária, tudo. É isto que eu tenho tentado trabalhar aqui na comunidade $\left(M_{6}\right)$.

A integralidade é manifestada nos relatos como uma necessidade profissional, e também do usuário, de ter consciência, para se (auto)cuidar.

Todos esses fatos evidentes que nos propõe a experiência cotidiana de se ter consciência retomam uma compreensão que está "na temática heideggeriana, de saber ultrapassar o sujeito dono de si, do mundo e do social. Colocar em questão a posição central do homem e da consciência" 19:78, ou seja, sublinhar que, além do sujeito e da consciência, 0 pensamento deveria estar atento ao despertar desse mundo e ao mistério que ele promove ${ }^{19}$.

A consciência do ente, do ser integral, o profissional olhar o outro com alteridade na produção do cuidado, ainda constitui um desafio, segundo $M_{6}$, pois "a gente ainda peca por ver o usuário por sistemas e, também, por trabalhar individualmente".

Embora a atenção integral esteja presente no discurso dos profissionais, ainda é desafiante encarar o usuário com alteridade e empatia. Os limites das ações em saúde evidenciados por muitos estudos e pelo cotidiano do serviço 
"têm desencadeado movimentos de reconhecimento da complexidade humana, haja vista a valorização das dimensões subjetivas"20:143.

Perspectivas e reflexões abrem-se nesse olhar do outro como uma pessoa que busca a saúde; muitos relatos se referem ao "fazer em saúde" como resposta à promoção. Isso também indica que o trabalho em saúde ainda está voltado para a cura ao agir sobre as pessoas em sofrimento, doentes, com experiências de vida complexas e cujas necessidades transbordam os muros das Unidades de Saúde. Mas o espaço do acolhimento no mundo dos Serviços de Saúde é apenas para uma parte dessas demandas, que podem ser mais amplas, pois a promoção de um bem-estar deve, necessariamente, estar expresso no cotidiano da moradia, da renda, do trabalho, da família.

Dessa forma, a relação entre a equipe Saúde da Família e a população adscrita deve estar fundamentada na construção de vínculo. Uma equipe deve buscar diariamente implantar mudanças na atenção à saúde, face às propostas de um modelo assistencial centrado no usuário, assentado no compromisso ético com a vida, com a promoção e a recuperação da saúde, visando a garantia do acesso aos cuidados necessários, o vínculo, a corresponsabilização para com o usuário, a integralidade da assistência e o monitoramento contínuo dos resultados alcançados ${ }^{21}$.

No âmbito de experimentar as possibilidades e habilidades profissionais, a integralidade é compreendida como uma ar ticulação de saberes, e que nos contextos deve ser um palco de diálogo entre as múltiplas vozes que os instituem e que se expressam na materialidade das práticas de distintos profissionais do campo da saúde:

A integralidade na verdade é uma forma de você trazer todos os componentes que a gente tem da saúde associado a outros profissionais, no sentido que, com isso, a gente possa dar uma melhor condição, uma qualidade de vida melhor às pessoas da comunidade. Então é o meu saber junto como saber e conhecimento do outro, você vaijuntando e vai facilitando [...] e integra o nosso conhecimento em prol da melhoria da qualidade de vida das pessoas do local $\left(F_{6}\right)$.

Conforme anunciado por $F_{6,}$ o espaço relacional entre os atores sociais na produção do cuidado cria um saber preocupado com a totalidade do outro, com destaque para a necessidade do diálogo entre o seu saber e os saberes dos outros profissionais, caracterizando o que chamamos de interdisciplinaridade.

A interdisciplinaridade pode ser compreendida como uma postura profissional que permite transitar o "espaço da diferença" com sentido de busca e de desvelamento das diferentes formas de se abordar a realidade. Nenhuma profissão e conhecimentos são absolutos, e a interdisciplinaridade é um princípio constituinte da diferença e da criaçãa ${ }^{22}$.

Dessa forma, a interdisciplinaridade é um princípio de troca ou completude de saberes e práticas que implica a valorização do cognitivo e do afetivo, da intuição e da sensibilidade própria e do outro, com possibilidade de ampliação do diálogo e do vínculo entre os componentes da equipe. Para o fisioterapeuta, os profissionais são sujeitos promotores do cuidado à saúde que detêm um saber, que se complementa com outros saberes, para desenvolver ações que possam promover melhor condição de existir, uma qualidade de vida para as pessoas sob seus cuidados.

0 trabalho em saúde pode ser concebido como uma coprodução constituída por um coletivo (equipe), cujas atividades tem como objeto o usuário, e não a doença, o núcleo central da racionalidade que nor teia as ações e conhecimento científico dos profissionais nos serviços de saúde. Definir como objeto de trabalho em saúde o usuário significa conceber os aspectos subjetivos, e não somente os objetivos, que 0 concretizam como sujeito social portador de aspirações, desejos e histórias de vida ${ }^{18: 24-25}$.

Reforçar-se, portanto, a necessidade de interação entre o conhecimento dos diferentes profissionais de saúde, para uma possibilidade de incorporação de novos objetos e tecnologias para uma atenção integral à saúde das famílias e da comunidade, numa construção coletiva da assistência na ESF.

\section{CONSIDERAÇÕES FINAIS}

A atenção ou cuidado nas organizações de saúde em geral é, por sua natureza, necessariamente multidisciplinar. Os profissionais da ESF demonstraram, em seus atos e em suas falas, a imprescindível colaboração que deve existir entre os vários trabalhadores, como operadores de tecnologias de saúde, para que o cuidado aconteça. A integralidade da atenção recebida resulta da forma como se articulam as práticas dos trabalhadores na saúde, isto é, fundamentadas no trabalho em equipe com ações interdisciplinares. Todavia, a integralidade do cuidado à saúde só pode ser obtida em rede. Pode haver algum grau de integralidade "focalizada", quando uma equipe, em um Serviço de Saúde, por meio de uma boa articulação de suas práticas, consegue escutar e atender, da melhor forma possível, as necessidades de saúde trazidas por cada um. É o que afirmam alguns profissionais ao mencionarem que, enquanto o usuário está sob os cuidados da equipe ESF, a integralidade é alcançada, se sua demanda não pedir ações mais complexas em saúde. Porém, a linha de cuidado pensada de forma plena atravessa os níveis de complexidade em diversos Serviços de Saúde.

Muitos são os fatores que promovem ações integrais, e os dados justificam a importância dada para o trabalho em 
equipe e o reconhecimento da necessidade do trabalho do outro, isto é, a complementaridade e a interdependência das ações para prestar uma assistência integral e resolutiva. Algumas equipes apresentaram ações interdisciplinares com uso das diferentes habilidades na identificação e resolução dos problemas. Outras convivem com ações individualizadas, mas referem a necessidade de responsabilidade compartilhada nas ações e decisões da equipe para alcançar a integralidade em saúde.

Vale enfatizar que esta pesquisa é um estudo de casos múltiplos holísticos; cada um dos casos constituiu uma entidade única, submetida a uma análise particular e contínua. Após análise criteriosa de cada caso, os dados apresentaram resultados semelhantes conferindo-lhes a replicação literal e uma capacidade de generalização. A validade externa fundamenta-se nas convergências dos dados, ou seja, nessa replicação literal; e as constatações dela decorrentes, por retratar uma situação real em seus múltiplos aspectos, permitem inferência e comparações com situações similares.

\section{REFERÊNCIAS}

1. Pinheiro R. Atenção básica à saúde: um olhar a partir das práticas de integralidade em saúde. REME rev. min. enferm. 2005 abr/jun; 9(2): 174-9.

2. Merhy EE. Um dos grandes desafios para os gestores do SUS: apostar em novos modos de fabricar modelos de atenção. In: 0 trabalho em saúde: olhando e experienciando o SUS no cotidiano: 0 debate no campo da saúde coletiva. $4^{a}$ ed. São Paulo: Editora Hucitec; 2007. p 15-35.

3. Viegas SMF, Hemmi APA, Santos RV, Penna CMM. 0 cotidiano da assistência ao cidadão na rede de saúde de Belo Horizonte. Physis (Rio J.) [online]. 2010 [Citado 2012 maio 28]; 20(3): 769-84. Disponivel em: $<$ http://www.scielo.br/pdf/physis/v20n3/v20n3a05.pdf>.

4. Starfield B. Atenção Primária e Saúde. In: Atenção primária: equilibrio entre necessidades de saúde, serviços e tecnologia. Brasilia(DF): UNESCO, Ministério da Saúde; 2002. p. 19-71.

5. Mattos RA. Princípios do Sistema Único de Saúde (SUS) e a humanização das práticas de saúde. Interface comun. saúde educ. [online]. 2009 [citado em???]; 13 (supl.1): 771-80. Disponível em: <http://www.scielo.br/pdf/icse/v13s1/a28v13s1.pdf>.
6. Valentim IVL, Kruel AJ. A importância da confiança interpessoal para a consolidação do Programa de Saúde da Família. Ciênc. saúde coletiva. 2007 Jun [Citado 2012 maio 28]; 12(3): 777-8. [periódico na internet]. Disponível em: <http://www.scielo.br/ scielo.php?script=sci_arttext $\&$ pid $=$ S 1413 $81232007000300028 \&$ lng $=$ en\&nrm $=i s o>$.

7. Viegas SMF. A integralidade no cotidiano da Estratégia Saúde da Família em municípios do Vale do Jequitinhonha-Minas Gerais [tese de doutorado]. Belo Horizonte(MG): Escola de Enfermagem/UFMG, 2010.

8. Maffesoli M. No fundo das aparências. Gurovitz BH, tradutor. Petrópolis(RJ): Vozes, 1996.

9.Yin RK. Estudo de caso: planejamento e métodos. Grassi D, tradutor. $3^{\text {a }}$ ed. Porto Alegre(RS): Bookman, 2005.

10. Bardin L. Análise de conteúdo. Lisboa(POR): Edições 70, 2008.

11. Araújo MBS, Rocha PM. Trabalho em equipe: um desafio para a consolidação da estratégia de saúde da família. Ciênc. saúde coletiva. 2007 mar/abr; 12(2): 455-64.

12. Bonet O. A Equipe de Saúde como um Sistema Cibernético. In: Pinheiro R, Mattos RA, organizadores. Construção social da demanda: direito à saúde, trabalho em equipe, participação e espaços públicos. Rio de Janeiro(RJ): CEPESC/UERJ, ABRASCO; 2005. p. 117-128.

13. Geertz C. A interpretação das culturas. Rio de Janeiro(RJ): Guanabara Koogan; 1989.

14. Dejours C. Subjetividade, trabalho e ação. Prod. [online]. 2004 dez. [acesso 2012 abril 18]; 14(3): 27-34. Disponível em: <http:/ /www.scielo.br/scielo.php?script=sci_arttext\&pid=S0103$65132004000300004 \& \operatorname{lng}=$ pt\&nrm $=$ iso $>$

15. Araújo JL, Paz EPA, Moreira TMM. Hermenêutica e o cuidado de saúde na hipertensão arterial realizado por enfermeiros na estratégia saúde da família. Esc. Anna Nery. 2010 jul/set; 14(3): 560-6.

16. Dejours C. Trabalho e Saúde Mental: da pesquisa à ação. In: Dejours C et al. Psicodinâmica do trabalho. São Paulo(SP): Atlas, 1994. p. 45-65.

17. Silva Júnior AG, Alves CA, Alves MGM. Entre Tramas e Redes: cuidado e integralidade. In: Pinheiro R, Mattos RA, organizadores. Construção social da demanda: direito à saúde, trabalho em equipe, participação e espaços públicos. Rio de Janeiro(RJ): CEPESC/ UERJ, ABRASCO; 2005. p. 33-46

18. Pinheiro R, Guizardi FL, Machado FRS, Gomes RS. Demanda em Saúde e Direito à Saúde: Liberdade ou necessidade? Algumas considerações sobre os nexos constituintes das práticas de integralidade. In: Pinheiro R, Mattos RA, organizadores. Construção social da demanda: direito à saúde, trabalho em equipe, participação e espaços públicos. Rio de Janeiro(RJ): CEPESC/ UERJ, ABRASC0; 2005. p. 11-31. 
19. Maffesoli, M. Le réenchantement du monde: une éthique pour notre temps. Paris(FRA): Éditions de La Table Ronde; 2007.

20. Gerhardt, TE, Riquinho DL, Rotoli A. Práticas terapêuticas e apoio social: implicações das dimensões subjetivas dos determinantes sociais no cuidado em saúde. In: Pinheiro R, Mattos RA, organizadores. Cuidar do cuidado: responsabilidade com a integralidade das ações de saúde. Rio de Janeiro(RJ): CEPESC, IMS/UERJ, ABRASC0; 2008. p 143-75.

21.Viegas SMF, Penna CMM. 0 SUS é universal mas vivemos de cotas. Ciênc. saúde coletiva [ internet] No prelo 2012 maio [Citado 2012 maio 28]; [aprox. 20 telas]. Disponível em: <http:// www.cienciaesaudecoletiva.com.br>.

22. Etges NJ. Ciência, interdisciplinaridade e educação. In: Jantsch $B L$, organizador. Interdisciplinaridade: para além da filosofia do sujeito. Petrópolis(RJ): Vozes; 2000. p. 51-84. 